University of Wollongong

Research Online

Faculty of Engineering - Papers (Archive)

Faculty of Engineering and Information

Sciences

April 2002

\title{
Modelling of particle breakage of coarse aggregates incorporating strength and dilatancy
}

Buddhima Indraratna

University of Wollongong, indra@uow.edu.au

Wadud Salim

University of Wollongong, wadud@uow.edu.au

Follow this and additional works at: https://ro.uow.edu.au/engpapers

Part of the Engineering Commons

https://ro.uow.edu.au/engpapers/393

\section{Recommended Citation}

Indraratna, Buddhima and Salim, Wadud: Modelling of particle breakage of coarse aggregates

incorporating strength and dilatancy 2002.

https://ro.uow.edu.au/engpapers/393

Research Online is the open access institutional repository for the University of Wollongong. For further information contact the UOW Library: research-pubs@uow.edu.au 


\section{Modelling of particle breakage of coarse aggregates incorporating strength and dilatancy}

\section{B. Indraratna and W. Salim}

The degradation of coarse aggregates under shear stresses and its influence on the shear strength is studied, considering the energy consumption by particle breakage during shearing. An analytical model is developed relating the deviator stress ratio, dilatancy, friction angle and particle breakage under triaxial loading. Large-scale triaxial testing of latite basalt has been conducted, and the extent of particle breakage during shearing has been quantified. The breakage of particles under monotonic triaxial loading has been considered within the scope of this paper, and the modelling of particle breakage of aggregates under cyclic loading will be presented in a follow-up paper. The results show that the breakage of particles continues to increase beyond the peak deviator stress. The energy consumption by particle breakage is non-linearly related to the particle breakage index. The model also evaluates the effect of particle breakage on the friction angle of ballast. This study sheds further light on the basic angle of friction, which is independent of the breakage of particles during shearing.

\section{NOTATION}

$B_{g} \quad$ particle breakage index

$\mathrm{d} E_{\mathrm{B}} \quad$ infinitesimal increment corresponding to $\delta E_{\mathrm{B}}$

$\mathrm{d} x_{i} \quad$ infinitesimal increment corresponding to $\delta x_{i}$

$\mathrm{d} y_{i} \quad$ infinitesimal increment corresponding to $\delta y_{i}$

$\mathrm{d} \varepsilon_{1} \quad$ infinitesimal increment of major principal strain

$\mathrm{d} \boldsymbol{\varepsilon}_{\mathrm{v}} \quad$ infinitesimal increment of volumetric strain

$\boldsymbol{F}_{1 i} \quad$ vertical force acting between two particles at contact $i$

$\boldsymbol{F}_{3 i} \quad$ horizontal force acting between two particles at contact $i$

$M \quad$ critical state friction ratio

$\boldsymbol{N}_{i} \quad$ normal force between two particles at contact $i$ acting normal to the slip direction

$n_{1}$ number of contacts in aggregate per unit length in the direction of $\boldsymbol{\sigma}_{1}^{\prime}$

$n_{2}$ number of contacts in aggregate per unit length in the direction of $\boldsymbol{\sigma}_{2}^{\prime}$

$n_{3} \quad$ number of contacts in aggregate per unit length in the direction of $\boldsymbol{\sigma}_{3}^{\prime}$

$\boldsymbol{p}^{\prime} \quad$ mean effective stress

$q$ deviator stress

$\boldsymbol{S}_{i} \quad$ shear resistance between two particles at contact $i$
$W_{\mathrm{k} i}$ percentage retained by weight in each grain size fraction before test

$W_{\mathrm{kf}} \quad$ percentage retained by weight in each grain size fraction after test

$\beta_{i} \quad$ angle of slip plane with the direction of major principal stress $\boldsymbol{\sigma}_{1}^{\prime}$ at contact $i$

$\beta_{\mathrm{c}} \quad$ value of $\beta_{i}$ for minimum energy ratio

$\Delta W_{\mathrm{k}}$ difference between $W_{\mathrm{k} i}$ and $W_{\mathrm{kf}}$

$\delta E_{B} \quad$ incremental energy consumed due to particle breakage during shearing in a unit volume of aggregate

$\delta E_{\mathrm{b} i}$ incremental energy consumed due to particle breakage during sliding between two particles at contact $i$

$\delta u_{i} \quad$ incremental displacement between two particles along slip plane at contact $i$

$\delta x_{i} \quad$ horizontal component of $\delta u_{i}$

$\delta y_{i} \quad$ vertical component of $\delta u_{i}$

$\delta \boldsymbol{\varepsilon}_{1} \quad$ finite increment of major principal strain

$\boldsymbol{\sigma}_{1}^{\prime} \quad$ major principal stress

$\boldsymbol{\sigma}_{2}^{\prime} \quad$ intermediate principal stress

$\boldsymbol{\sigma}_{3}^{\prime} \quad$ minor principal stress

$\phi_{\mathrm{cv}} \quad$ friction angle of an aggregate at constant volume

$\phi_{\mathrm{cs}} \quad$ friction angle of an aggregate at critical state

$\phi_{\mathrm{f}} \quad$ basic friction angle of an aggregate excluding particle breakage and dilatancy effects

$\phi_{\mathrm{fb}} \quad$ apparent friction angle excluding dilatancy effect but including particle breakage effect

$\phi_{\max }$ friction angle of an aggregate at maximum deviator stress

$\phi_{\mathrm{p}} \quad$ friction angle of an aggregate at peak deviator stress

$\phi_{\mu} \quad$ interparticle friction angle between two particles

\section{INTRODUCTION}

The degradation of aggregates during shearing has always been a concern for researchers and engineers, and especially in the construction and maintenance of high rockfill dams, unbound roads and rail tracks. Limited research is found in the literature regarding the particle breakage of coarse granular aggregates during shearing, or degradation modelling, either analytical or numerical. Although granular aggregates are subjected to cyclic loading in unbound roads and rail tracks, the study of particle breakage and its effects on the shear strength of aggregates under monotonic triaxial loading would improve our insight into and understanding of the behaviour of aggregates under complex cyclic loading. Within the scope of 
this paper, the authors have developed an analytical model of particle breakage of coarse aggregates (latite basalt) under a monotonic triaxial loading condition. The model may still be applied in rail track engineering, where the analysis corresponds to the first-stage loading of a repeated (cyclic) loading scheme typically applied by the passage of a train on a rail-ballast track. The authors are in the process of extending the current model to incorporate cyclic loading, so that the degradation of coarse aggregates can be modelled after numerous cycles of repeated loading. The extended model will be published in a follow-up paper.

Many researchers consider the shear strength of granular materials, and particularly of sand, to be dependent upon the basic friction angle and dilatancy during shearing. ${ }^{1,2}$ It is shown that the shear strength increases with increasing dilatancy, which tends to decrease with increasing confining pressure. Lee and Seed ${ }^{3}$ demonstrated that, under high pressure, the shear strength of sand increased while the dilatancy decreased. They attributed this observation to particle crushing and rearrangement during shearing. Miura and 0-hara ${ }^{4}$ indicated that particle breakage could be significant for low-strength granular materials such as decomposed granite, even under low confining pressure. McDowell et al. ${ }^{5}$ developed a conceptual model of the probability of fracture of particles in an aggregate based on Weibull ${ }^{6}$ statistics of fracture. McDowell et al. ${ }^{5}$ and McDowell and Bolton ${ }^{7}$ added a fracture energy term to the original Cam Clay work energy equation. ${ }^{8,9}$ However, they considered the breakage of particles and the fracture energy only for the special case of onedimensional compression. Indraratna et al. ${ }^{10}$ developed an empirical relationship between the peak stress ratio, peak friction angle and particle breakage for ballast aggregates. Ueng and Chen ${ }^{11}$ presented an analytical formulation for peak principal stress ratio $\left(\boldsymbol{\sigma}_{1}^{\prime} / \boldsymbol{\sigma}_{3}^{\prime}\right)$ of sand, considering dilatancy and particle breakage during shearing. In this paper, the effect of particle breakage on the shear strength of coarse aggregates is studied, and an analytical model incorporating the deviator stress ratio $\left(\boldsymbol{q} / \boldsymbol{p}^{\prime}\right)$, dilatancy, friction angle and the energy consumption due to particle breakage is developed for general triaxial shearing based on the MohrCoulomb friction theory. Laboratory test results are used in conjunction with the analytical model to explain the effects of particle breakage, dilatancy and confining pressure on the strength and friction angle of coarse aggregates.

Various methods have been used in the past to quantify the breakage of particles during shearing. Marsal ${ }^{12}$ developed an index for particle breakage, $B_{\mathrm{g}}$, where the difference $\left(\Delta W_{\mathrm{k}}\right)$ between the percentage retained by weight of each grain size fraction before the test $\left(W_{\mathrm{ki}}\right)$ and after the test $\left(W_{\mathrm{kf}}\right)$ was plotted against the aperture of the lower sieve corresponding to that fraction. In this technique, the particle breakage index, $B_{\mathrm{g}}$, is equal to the sum of the positive values of $\Delta W_{\mathrm{k}}$, expressed as a percentage. Hardin ${ }^{13}$ introduced an alternative index for quantifying the total breakage, $B_{\mathrm{t}}$, whereas Miura and 0-hara ${ }^{4}$ used the surface area increment $(\Delta S)$ as an indicator of particle breakage. Hardin's total breakage $\left(B_{\mathrm{t}}\right)$ parameter is the area between the gradation curves before and after loading up to $0.074 \mathrm{~mm}$ particle size, and requires a planimeter for accurate area measurement. The surface area increment, $\Delta S$, as the indicator of particle breakage is also based on mass gradation curves and requires some assumptions for calculating the specific surface area of different particle (sieve) size. Having compared the various alternative methods, the particle breakage index $B_{\mathrm{g}}$, proposed by Marsal, ${ }^{12}$ has been adopted in this study owing to its simplicity and reliability, in order to quantify the degradation of aggregates during shearing.

\section{THEORETICAL DEVELOPMENT}

Since triaxial testing is one of the most versatile and useful laboratory methods for obtaining strength and deformation parameters of geomaterials, the interparticle forces and the deformations occurring in a cylindrical triaxial specimen have been considered as the basis for developing the stress-strain relationship of coarse aggregates. Fig. 1 shows an axisymmetric triaxial specimen subjected to drained compression loading. The vertical force, $\boldsymbol{F}_{1 i}$, and the horizontal force, $\boldsymbol{F}_{3 i}$, are acting at the contact $i$ between two typical particles, which are sliding relative to each other under the applied loading. The sliding plane makes an angle $\beta_{i}$ with the major principal stress, $\boldsymbol{\sigma}_{1}^{\prime}$. If $\boldsymbol{N}_{i}$ and $\boldsymbol{S}_{i}$ are the normal force and shear resistance respectively, then by resolving the forces $\boldsymbol{F}_{1 i}$ and $\boldsymbol{F}_{3 i}$ it can be shown that

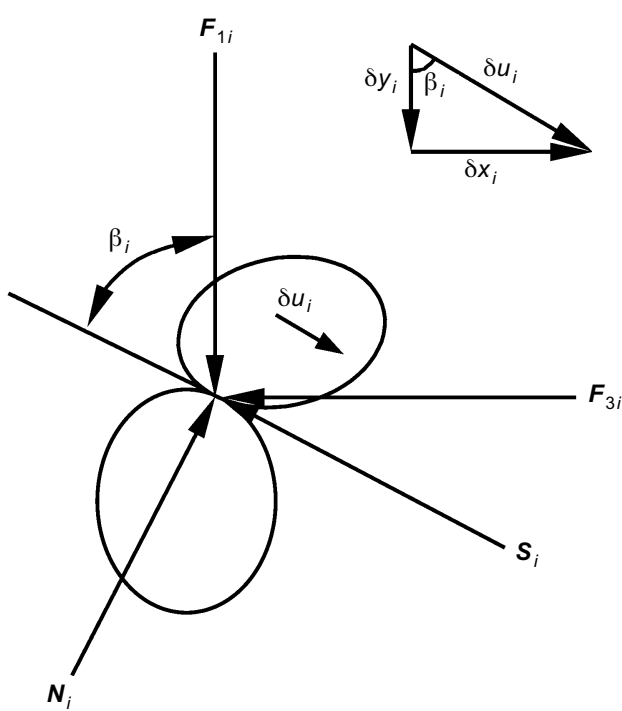

(b) 


$$
\boldsymbol{N}_{i}=\boldsymbol{F}_{1 i} \sin \beta_{i}+\boldsymbol{F}_{3 i} \cos \beta_{i}
$$

$$
\boldsymbol{S}_{i}=\boldsymbol{F}_{1 i} \cos \beta_{i}-\boldsymbol{F}_{3 i} \sin \beta_{i}
$$

The shear resistance, $\boldsymbol{S}_{i}$, can be expressed by the MohrCoulomb theory, assuming no cohesion $(c=0)$ between the coarse granular particles. Hence

\begin{tabular}{|l|l|}
\hline 3 & $S_{i}=N_{i} \tan \phi_{\mu}$ \\
\hline
\end{tabular}

where $\phi_{u}$ is the friction angle between two particles. If $\delta u_{i}$ is the incremental displacement at contact $i$ in the direction of sliding, then the horizontal component $\delta x_{i}$ and vertical component $\delta y_{i}$ of the displacement $\delta u_{i}$ can be expressed by the following relationships

\begin{tabular}{|l|l|}
\hline 4 & $\delta x_{i}=\delta u_{i} \sin \beta_{i}$ \\
\hline
\end{tabular}

\begin{tabular}{|l|l|}
\hline 5 & $\delta y_{i}=\delta u_{i} \cos \beta_{i}$ \\
\hline
\end{tabular}

\begin{tabular}{|l|l|}
\hline 6 & $\delta x_{i}=\delta y_{i} \tan \beta_{i}$ \\
\hline
\end{tabular}

If particle breakage is accompanied with sliding during shearing, then one can assume that the total work done by $\boldsymbol{F}_{1 i}$ and $\boldsymbol{F}_{3 i}$ at contact $i$ is spent on overcoming frictional resistance and the breakage of particles. Hence

\begin{tabular}{|l|l|}
\hline 7 & $\boldsymbol{F}_{1 i} \delta y_{i}-\boldsymbol{F}_{3 \mathrm{i}} \delta x_{i}=\boldsymbol{N}_{\boldsymbol{i}} \tan \phi_{\mu} \delta u_{i}+\delta E_{\mathrm{bi}}$ \\
\hline
\end{tabular}

where $\delta E_{\mathrm{b} i}$ is the incremental amount of energy spent on particle breakage at contact $i$ during the movement $\delta u_{i}$.

Substituting equations (1), (5) and (6) in equation (7) gives

\begin{tabular}{|c|r|}
\hline $\boldsymbol{F}_{1 i} \delta y_{i}-\boldsymbol{F}_{3 i} \delta y_{i} \tan \beta_{i}=$ & $\boldsymbol{F}_{1 i} \delta y_{i} \tan \beta_{i} \tan \phi_{\mu}$ \\
& $+\boldsymbol{F}_{3 i} \delta y_{i} \tan \phi_{\mu}+\delta E_{\mathrm{b} i}$ \\
\hline
\end{tabular}

Assuming that $n_{1}, n_{2}$ and $n_{3}$ are the average number of contacts per unit length in the directions of the three principal stresses, $\boldsymbol{\sigma}_{1}^{\prime}, \boldsymbol{\sigma}_{2}^{\prime}$ and $\boldsymbol{\sigma}_{3}^{\prime}$ respectively, the average contact forces and the vertical displacement component can be written as

\begin{tabular}{|l|l|}
\hline 9 & $\boldsymbol{F}_{1 i}=\frac{\boldsymbol{\sigma}_{1}^{\prime}}{n_{2} n_{3}}$ \\
\hline
\end{tabular}

\begin{tabular}{|l|l|}
\hline 10 & $\boldsymbol{F}_{3 i}=\frac{\boldsymbol{\sigma}_{3}^{\prime}}{n_{1} n_{2}}$ \\
\hline
\end{tabular}

$$
\delta y_{i}=\frac{\delta \varepsilon_{1}}{n_{1}}
$$

where $\delta \varepsilon_{1}$ is the incremental major principal strain.

Substituting equations (9), (10) and (11) in equation (8), and multiplying both sides by $n_{1} n_{2} n_{3}$, gives

$$
\begin{aligned}
\boldsymbol{\sigma}_{1}^{\prime} \delta \boldsymbol{\varepsilon}_{1}-\boldsymbol{\sigma}_{3}^{\prime} \delta \boldsymbol{\varepsilon}_{1}\left(\frac{n_{3}}{n_{1}}\right) \tan \beta_{i}=\boldsymbol{\sigma}_{1}^{\prime} \delta \varepsilon_{1} \tan \beta_{i} \tan \phi_{\mu} \\
+\boldsymbol{\sigma}_{3}^{\prime} \delta \varepsilon_{1}\left(\frac{n_{3}}{n_{1}}\right) \tan \phi_{\mu}+\delta E_{\mathrm{bi}}\left(n_{1} n_{2} n_{3}\right)
\end{aligned}
$$

where the product $n_{1} n_{2} n_{3}$ represents the total number of contacts in a unit volume of granular aggregates. Let $\delta E_{\mathrm{B}}=\delta E_{\mathrm{b} i}\left(n_{1} n_{2} n_{3}\right)=$ incremental energy spent on particle breakage per unit volume of aggregates during the incremental strain $\delta \varepsilon_{1}$, and $r_{n}=\left(n_{3} / n_{1}\right)$ : then equation (12) becomes

$$
\begin{aligned}
\boldsymbol{\sigma}_{1}^{\prime} \delta \varepsilon_{1}-\boldsymbol{\sigma}_{3}^{\prime} \delta \varepsilon_{1} r_{n} \tan \beta_{i}= & \boldsymbol{\sigma}_{1}^{\prime} \delta \varepsilon_{1} \tan \beta_{i} \tan \phi_{\mu} \\
& +\boldsymbol{\sigma}_{3}^{\prime} \delta \varepsilon_{1} r_{n} \tan \phi_{\mu}+\delta E_{\mathrm{B}}
\end{aligned}
$$

Using the conventional stress parameters $\boldsymbol{p}^{\prime}$ (mean effective stress) and $\boldsymbol{q}$ (deviator stress), instead of $\boldsymbol{\sigma}_{1}^{\prime}$ and $\boldsymbol{\sigma}_{3}^{\prime}$, equation (13) can be rewritten as follows:

$$
\begin{aligned}
\left(\boldsymbol{p}^{\prime}+\frac{2 \boldsymbol{q}}{3}\right) \delta \boldsymbol{\varepsilon}_{1} & -\left(\boldsymbol{p}^{\prime}-\frac{\boldsymbol{q}}{3}\right) \delta \boldsymbol{\varepsilon}_{1} r_{n} \tan \beta_{i} \\
= & \left(\boldsymbol{p}^{\prime}+\frac{2 \boldsymbol{q}}{3}\right) \delta \boldsymbol{\varepsilon}_{1} \tan \beta_{i} \tan \phi_{\mu} \\
& +\left(\boldsymbol{p}^{\prime}-\frac{\boldsymbol{q}}{3}\right) \delta \boldsymbol{\varepsilon}_{1} r_{n} \tan \phi_{\mu}+\delta E_{B}
\end{aligned}
$$

where $\boldsymbol{p}^{\prime}=\left(\boldsymbol{\sigma}_{1}^{\prime}+2 \boldsymbol{\sigma}_{3}^{\prime}\right) / 3$ and $\boldsymbol{q}=\boldsymbol{\sigma}_{1}^{\prime}-\boldsymbol{\sigma}_{3}^{\prime}$.

Rearranging equation (14), the deviator stress ratio becomes

$$
\begin{array}{|l|l|}
\frac{\boldsymbol{q}}{\boldsymbol{p}^{\prime}}= & \frac{r_{n} \tan \left(\beta_{i}+\phi_{\mu}\right)-1}{\left[\frac{2}{3}+\frac{1}{3} r_{n} \tan \left(\beta_{i}+\phi_{\mu}\right)\right]} \\
& +\frac{\delta E_{B}}{\boldsymbol{p}^{\prime} \delta \boldsymbol{\varepsilon}_{1}\left[\frac{2}{3}+\frac{1}{3} r_{n} \tan \left(\beta_{i}+\phi_{\mu}\right)\right]\left[1-\tan \beta_{i} \tan \phi_{\mu}\right]}
\end{array}
$$

In the case of an infinitesimal increment of major principal strain (i.e. $\delta \varepsilon_{1} \rightarrow 0$ ), $\delta \varepsilon_{1}$ should be replaced by the differential increment $\mathrm{d} \varepsilon_{1}$, and the corresponding increments of $\delta E_{\mathrm{B}}, \delta y_{i}$ and $\delta x_{i}$ should be replaced by the differential increments $\mathrm{d} E_{\mathrm{B}}$, $\mathrm{d} y_{i}$ and $\mathrm{d} x_{i}$ respectively. Thus, for the limiting case $\left(\delta \varepsilon_{1} \rightarrow 0\right)$, the term $\left(\delta E_{\mathrm{B}} / \delta \boldsymbol{\varepsilon}_{1}\right)$ on the right-hand side of equation (15) becomes the derivative $\left(\mathrm{d} E_{\mathrm{B}} / \mathrm{d} \boldsymbol{\varepsilon}_{1}\right)$, and represents the rate of energy consumption due to particle breakage during shearing.

Rowe $^{2}$ suggested that, for granular aggregates, the interparticle friction angle, $\phi_{\mu}$, should be replaced by $\phi_{\mathrm{f}}$, which is the angle 
of friction after correction for dilatancy. The value of $\phi_{\mathrm{f}}$ varies from $\phi_{\mu}$ for very dense materials to $\phi_{\mathrm{cv}}$ for very loose materials at constant volume. The difference between $\phi_{\mathrm{f}}$ and $\phi_{\mu}$ was attributed to the energy spent on the process of rearrangement of particles during shearing.

According to the minimum energy ratio principle, shear deformation of the aggregate mass will occur when, at each contact $i$, the energy ratio $\left(E R_{i}\right)$ of the work done by $\boldsymbol{F}_{1 i}$ to that by $\boldsymbol{F}_{3 i}$ (i.e. $E R_{i}=\boldsymbol{F}_{1 i} \delta y_{i} / \boldsymbol{F}_{3 i} \delta x_{i}$ ) is a minimum. By expanding the expression for $E R_{i}$ and letting $\mathrm{d}\left(E R_{i}\right) / \mathrm{d} \beta_{i}=0$, one can determine the sliding direction at contact $i$ (i.e. $\beta_{i}=\beta_{\mathrm{c}}$ ) for the minimum energy ratio condition. In other words, when $E R_{i}=E R_{\min }, \beta_{i}=\beta_{c}$. Using this minimum energy ratio principle, Ueng and Chen ${ }^{11}$ proposed the values of $r_{n}$ and $\beta_{c}$ as given in the following two expressions:

\begin{tabular}{|l|l|}
\hline $16 \mathrm{a}$ & $r_{n}=\frac{1-\frac{d \varepsilon_{\mathrm{v}}}{d \varepsilon_{1}}}{\tan \beta_{\mathrm{c}}}$ \\
\hline
\end{tabular}

\begin{tabular}{|l|l|}
\hline $16 \mathrm{~b}$ & $\beta_{\mathrm{c}}=45^{\circ}-\frac{\phi_{\mathrm{f}}}{2}$ \\
\hline
\end{tabular}

where $\mathrm{d} \boldsymbol{\varepsilon}_{\mathrm{v}}$ is the infinitesimal increment of volumetric strain (compression is taken as positive) of the triaxial specimen corresponding to $\mathrm{d} \varepsilon_{1}$.

Substituting equations (16a) and (16b), $\phi_{\mu}$ by $\phi_{\mathrm{f}}$ and $\beta_{i}=\beta_{\mathrm{c}}$ in equation (15), and using the differential incremental terms, the deviator stress ratio becomes

$$
\begin{aligned}
\frac{\boldsymbol{q}}{\boldsymbol{p}^{\prime}}= & \frac{\left(1-\frac{d \boldsymbol{\varepsilon}_{\mathrm{v}}}{d \boldsymbol{\varepsilon}_{1}}\right) \tan ^{2}\left(45^{\circ}+\frac{\phi_{\mathrm{f}}}{2}\right)-1}{\left[\frac{2}{3}+\frac{1}{3}\left(1-\frac{\mathrm{d} \boldsymbol{\varepsilon}_{\mathrm{v}}}{\mathrm{d} \boldsymbol{\varepsilon}_{1}}\right) \tan ^{2}\left(45^{\circ}+\frac{\phi_{\mathrm{f}}}{2}\right)\right]} \\
& +\frac{\mathrm{d} E_{\mathrm{B}}\left(1+\sin \phi_{\mathrm{f}}\right)}{\boldsymbol{p}^{\prime} \mathrm{d} \boldsymbol{\varepsilon}_{1}\left[\frac{2}{3}+\frac{1}{3}\left(1-\frac{\mathrm{d} \boldsymbol{\varepsilon}_{\mathrm{v}}}{\mathrm{d} \boldsymbol{\varepsilon}_{1}}\right) \tan ^{2}\left(45^{\circ}+\frac{\phi_{\mathrm{f}}}{2}\right)\right]}
\end{aligned}
$$

The quantity ( $\left.1-\mathrm{d} \boldsymbol{\varepsilon}_{\mathrm{v}} / \mathrm{d} \boldsymbol{\varepsilon}_{1}\right)$ represents dilatancy during shearing. In this study, $\phi_{\mathrm{f}}$ is considered as the basic friction angle of aggregates, which excludes the effects of both dilatancy and particle breakage. The energy consumption due to particle breakage may be related to the particle breakage index $B_{\mathrm{g}}$ (defined earlier) as shown below:

\begin{tabular}{|l|l|}
\hline 18 & $\mathrm{~d} E_{\mathrm{B}}=f\left(\mathrm{~d} B_{\mathrm{g}}\right)$ \\
\hline
\end{tabular}

where $\mathrm{d} B_{\mathrm{g}}$ is the differential increment of breakage index corresponding to $\mathrm{d} \boldsymbol{\varepsilon}_{1}$. Combining equations (17) and (18) provides

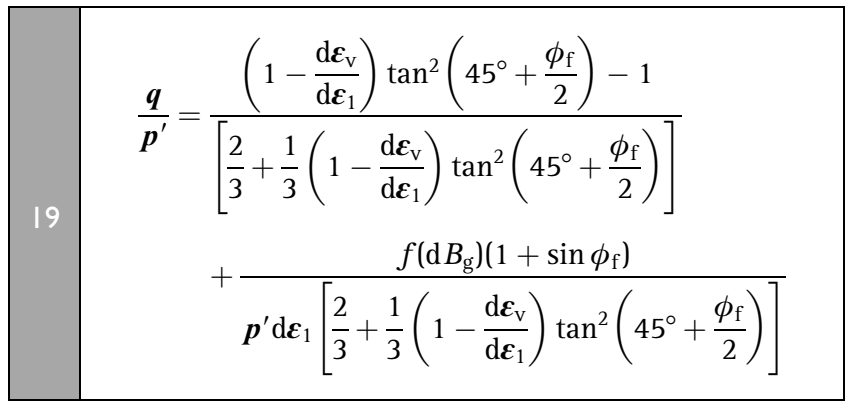

The function $f\left(\mathrm{~d} B_{\mathrm{g}}\right)$ in equation (19) remains to be determined based on laboratory triaxial testing.

It is interesting to note that the proposed model simplifies to the critical-state equation when the breakage of particles is ignored. In conventional critical-state soil mechanics, ${ }^{9}$ the breakage of particles during shearing is not taken into consideration. At the critical state, particles will continuously deform at constant stress and constant volume. If the breakage of particles is ignored (i.e. $\mathrm{d} E_{\mathrm{B}}=f\left(\mathrm{~d} B_{\mathrm{g}}\right)=0$ ) at critical state (i.e. $\mathrm{d} \boldsymbol{p}^{\prime}=\mathrm{d} \boldsymbol{q}=\mathrm{d} \boldsymbol{\varepsilon}_{\mathrm{v}}=0$ and $\phi_{\mathrm{f}}=\phi_{\mathrm{cs}}$ ), then equations (17) and (19) are reduced to the following critical state relationships:

$$
20 \quad\left(\frac{\boldsymbol{q}}{\boldsymbol{p}^{\prime}}\right)_{\mathrm{cs}}=\frac{\tan ^{2}\left(45^{\circ}+\frac{\phi_{\mathrm{cs}}}{2}\right)-1}{\frac{2}{3}+\frac{1}{3} \tan ^{2}\left(45^{\circ}+\frac{\phi_{\mathrm{cs}}}{2}\right)}=\frac{6 \sin \phi_{\mathrm{cs}}}{3-\sin \phi_{\mathrm{cs}}}=M
$$

\section{LABORATORY INVESTIGATIONS}

Testing of coarse aggregates (at the size of railway ballast) in small (conventional) triaxial equipment can lead to misleading strength-deformation characteristics. ${ }^{10}$ It is therefore essential to test such coarse aggregates in a large-scale triaxial apparatus. With this in view, a large-scale triaxial apparatus (Fig. 2) has been designed and built at the University of Wollongong. Several consolidated drained triaxial compression tests were carried out on latite aggregates. The developed model has been applied to the test results to explain the effects of particle breakage, dilatancy and confining pressure on the friction angle of latite basalt.

\section{I. Large-scale triaxial apparatus}

A large-scale triaxial apparatus (Fig. 2), which can accommodate specimens $300 \mathrm{~mm}$ diameter and $600 \mathrm{~mm}$ high, was used for investigating the strength-deformation and degradation characteristics of latite basalt. The main components of the apparatus are the triaxial chamber, the axial loading unit, the air pressure and water control unit, the pore water pressure measurement system, the axial deformation measuring device and the volumetric change measurement unit. The volume change of the specimen during consolidation and drained shearing was measured by a coaxial piston located within a small cylindrical chamber (connected to the main cell), in which the smooth piston moves upwards or downwards depending on volume increase or decrease. Further details of the equipment are given elsewhere. ${ }^{10,14}$

\subsection{Material properties}

The aggregates tested in this study are crushed volcanic basalt (latite) obtained from a quarry in New South Wales (NSW), 


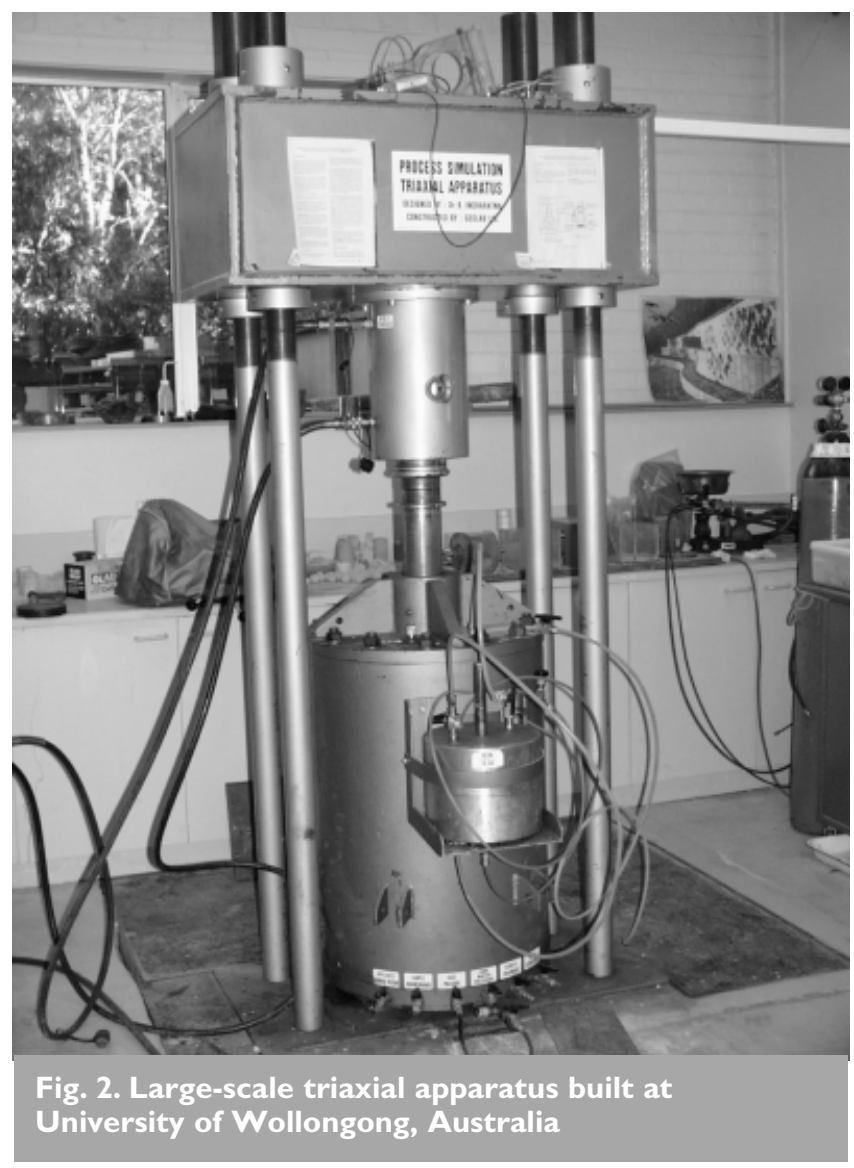

Australia. The physical properties of latite basalt are given in Table 1 . The aggregate crushing value is the ratio of the mass of crushed particles passing a reference sieve to the total mass of aggregate, expressed as a percentage, after being subjected to a specified load (AS 1141.21 ${ }^{15}$ ). The Los Angeles abrasion value is the ratio of mass lost due to abrasion (passing a $1.70 \mathrm{~mm}$ sieve) to the total mass of aggregate, expressed as a percentage (AS $1141.23^{16}$ ). The wet attrition value is the ratio of loss of mass (passing a $2.36 \mathrm{~mm}$ sieve) to the total mass of aggregate in a wet attrition test (AS $1141.27^{17}$ ). The point load strength index, $I_{\mathrm{s}(50)}$, was determined according to the AS 4133.4.1 method. ${ }^{18}$ The uniaxial compressive strength of the parent rock was determined according to the AS 4133.4.2 method. ${ }^{19}$ The flakiness index is the percentage by mass of flaky particles, and was measured according to the AS 1141.15 method. ${ }^{20}$ The proportion of misshapen particles is the

\begin{tabular}{|c|c|c|c|}
\hline $\begin{array}{l}\text { Characteristic test } \\
\text { results }\end{array}$ & Units & Value & $\begin{array}{c}\text { Test methods } \\
\text { (Australian } \\
\text { Standard) }\end{array}$ \\
\hline $\begin{array}{l}\text { Aggregate crushing value } \\
\text { Los Angeles abrasion } \\
\text { Wet attrition } \\
\text { Point load strength index } \\
\text { Compressive strength } \\
\text { Flakiness Index } \\
\text { Misshapen particles }\end{array}$ & $\begin{array}{c}\% \\
\% \\
\% \\
\% \\
\mathrm{MPa} \\
\mathrm{MPa} \\
\% \\
\%\end{array}$ & $\begin{array}{l}12 \\
15 \\
8 \\
5 \cdot 39 \\
130 \\
25 \\
20\end{array}$ & $\begin{array}{l}\text { AS } 1141.21^{15} \\
\text { AS } 1141.23^{16} \\
\text { AS } 1141.27^{17} \\
\text { AS } 4133.4 .1^{18} \\
\text { AS } 4133.4 .2^{19} \\
\text { AS } 1141.15^{20} \\
\text { AS } 1141.14^{21}\end{array}$ \\
\hline
\end{tabular}

percentage of flat, elongated, and flat and elongated particles in an aggregate mass, and was measured according to AS 1141.14. ${ }^{21}$ The grain size distribution of aggregates is presented in Fig. 3. The size of particles varied between $19 \mathrm{~mm}$ and $53 \mathrm{~mm}$ with a mean size $\left(d_{50}\right)$ of $37 \mathrm{~mm}$. The particle size distribution of latite basalt after the test is also shown in Fig. 3 to indicate typical particle degradation.

\subsection{Preparation of specimens and test procedure}

The specimen was prepared inside a $5 \mathrm{~mm}$ thick rubber membrane placed within a split cylindrical mould. Compaction of aggregates was carried out in several layers using a vibratory hammer. The dry unit weight of the specimens varied in the range $15 \cdot 3-15 \cdot 4 \mathrm{kN} / \mathrm{m}^{3}$. The corresponding initial void ratio $\left(e_{0}\right)$ was about $0 \cdot 72$. During laboratory compaction, a $4 \mathrm{~mm}$ thick rubber pad was used at the tip of the hammer to minimise the risk of breakage of particles during vibration.

After placing the compacted specimen inside the triaxial cell, the cell was filled with water by an upward flow from the bottom plate and left overnight for saturation. Consolidation of the specimen was commenced after achieving the pore pressure parameter, $B>95 \%$. The stress measurements were corrected for the membrane effect as described by Duncan and Seed. ${ }^{22}$ Fully drained compression tests were conducted at relatively low to moderate confining pressures (10-300 kPa). Ballast in rail track is usually under low confinement produced by the weight of crib ballast, sleeper and track superstructure.

However, the stresses generated during maintenance operations (tamping) could be moderate to high values. The range of confining pressures for laboratory investigations was selected to represent the typical ballast confinement in the track. All tests were carried out in this study at an axial strain rate of $0 \cdot 25 \% / \mathrm{min}$, which was sufficiently low to dissipate excess pore pressures developed during shearing. Each specimen was sieved

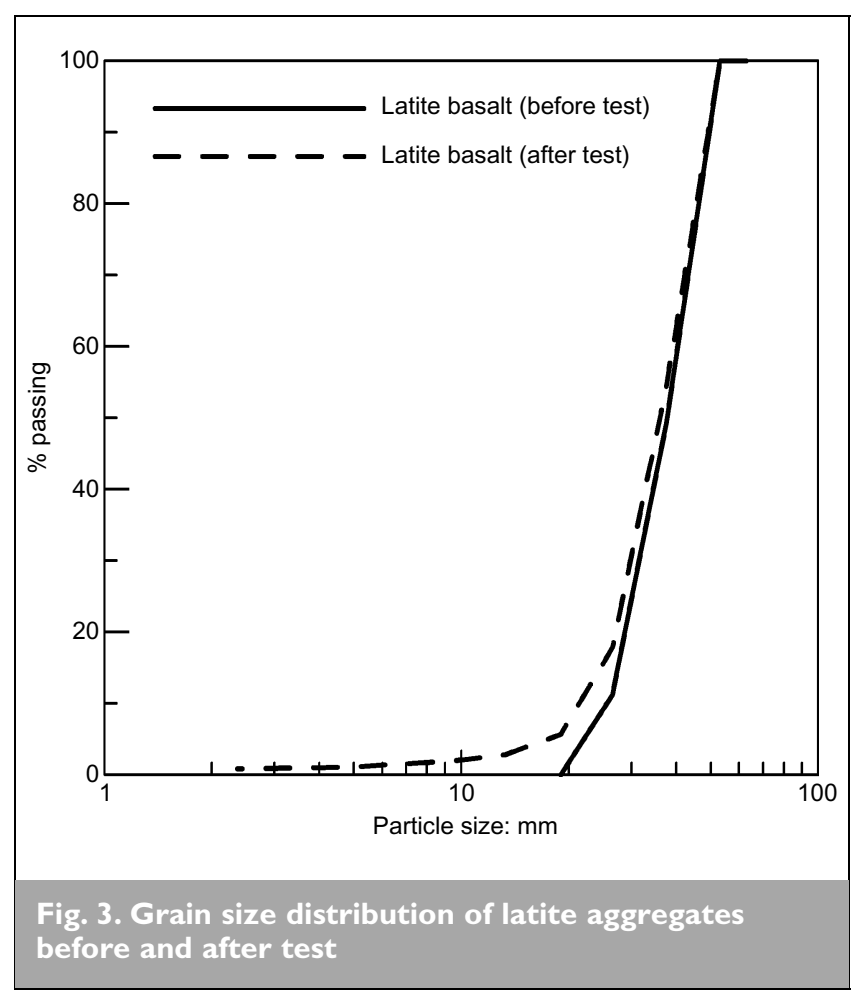


before and after the test, and the changes in particle size were recorded to quantify particle breakage.

\section{EXPERIMENTAL RESULTS}

The latite aggregates were degraded owing to the application of monotonic shear stresses. It is important to note that the stresses applied in this study were sufficiently low compared with the compressive strength (130 MPa) of the parent rock. However, owing to the stress concentrations at the sharp corners and angles, the applied stresses were sufficient to cause breakage of asperities, which is reflected in the change of the particle size distribution curve shown in Fig. 3. Visual inspection of the aggregates recovered after testing confirmed that the degradation process under the current loading scheme was mainly of wear rather than bulk fracture.

The change in particle size $\left(\Delta W_{\mathrm{k}}\right)$ of aggregates after $20 \%$ axial straining in the large-scale triaxial apparatus is shown in Fig. 4 for the two limiting confining pressures (10 kPa and $300 \mathrm{kPa}$ ) used in this study. The plots of $\Delta W_{\mathrm{k}}$ for the intermediate confining pressures follow a similar trend as in Fig. 4, and are therefore not shown here. Fig. 4 indicates that the change in particle size $\left(\Delta W_{\mathrm{k}}\right)$ increases with increasing confining pressure, and that larger particles in the range $30-45 \mathrm{~mm}$ size (i.e. close to the positive peak) are most vulnerable to degradation.

The breakage indices $\left(B_{\mathrm{g}}\right)$ of latite basalt obtained after terminating tests at various axial strains $(0 \%, 5 \%, 10 \%$ and $20 \%)$ are plotted in Fig. 5. The failure strains $\left(\varepsilon_{1 \mathrm{f}}\right)$ are indicated on the plots, and the locus of failure strains is also shown. Here, the failure strain is defined as the axial strain at peak deviator stress. Fig. 5 demonstrates clearly that the degree of particle breakage increases with increasing axial strain, and with higher confining pressure. Particle breakage continues to increase even after the peak deviator stress. The rate of particle

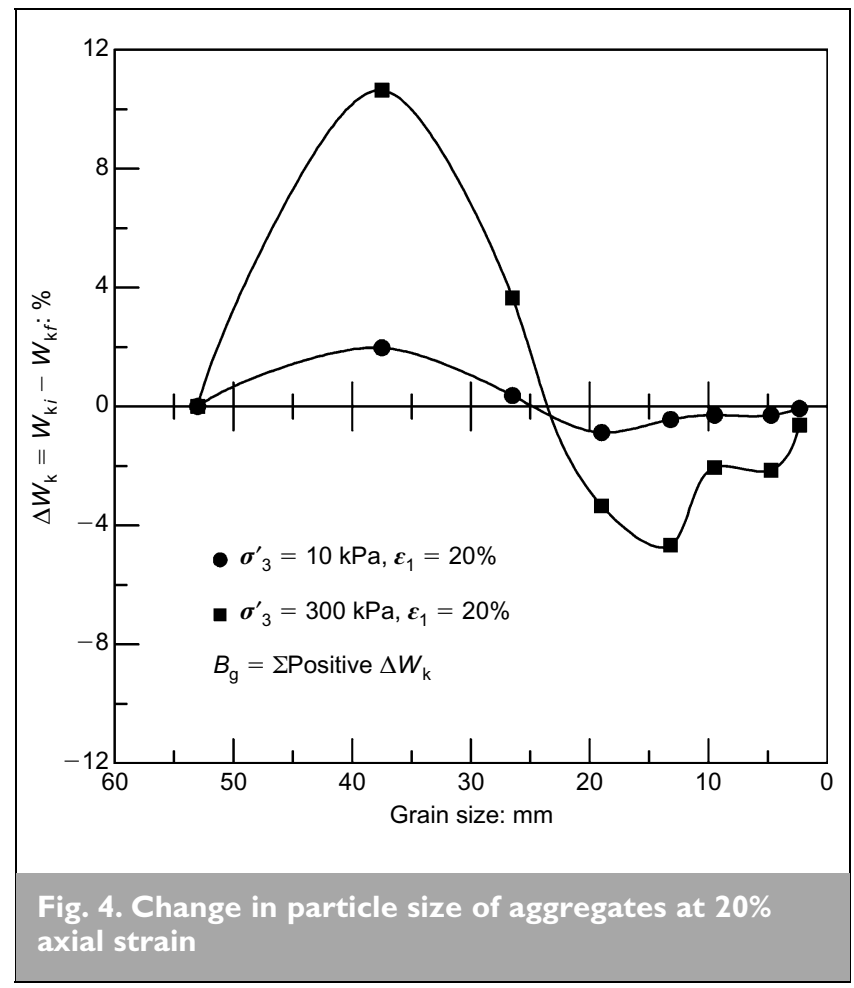

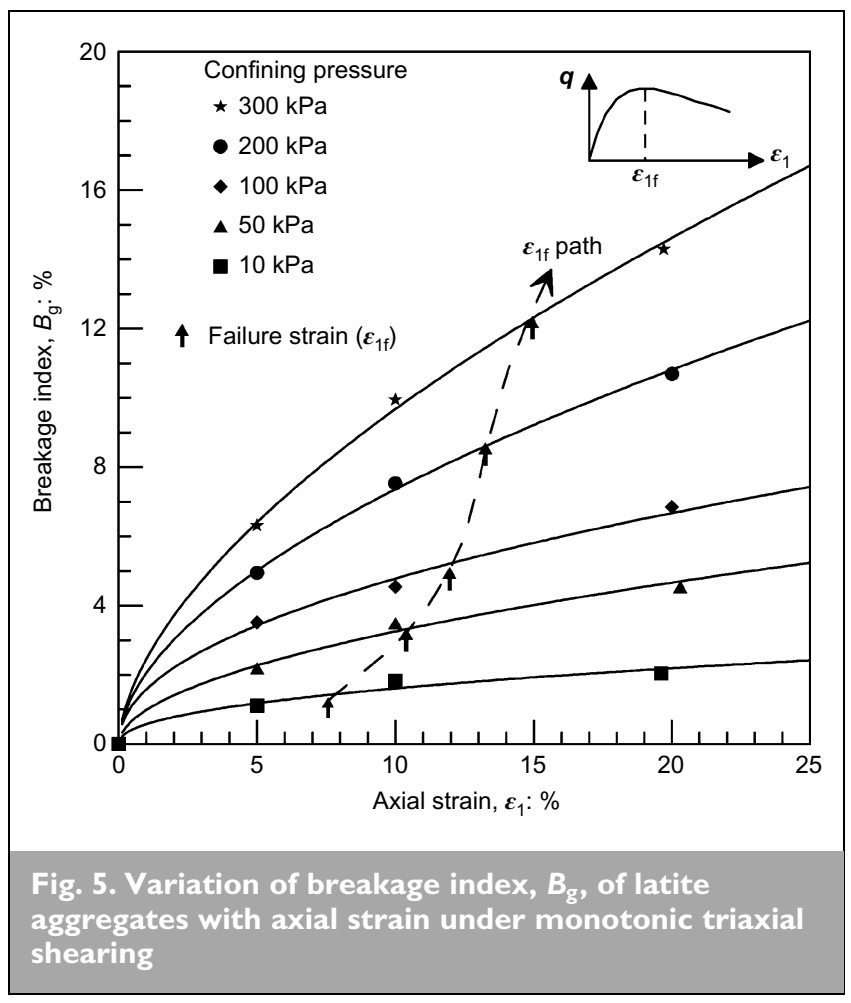

breakage $\left(\mathrm{d} B_{\mathrm{g}} / \mathrm{d} \boldsymbol{\varepsilon}_{1}\right)$ decreases with increasing axial strain, but increases with increasing confining pressure.

Figure 6 shows the deviator stress ratio $\left(\boldsymbol{q} / \boldsymbol{p}^{\prime}\right)_{\mathrm{f}}$ against dilatancy $\left(1-\mathrm{d} \boldsymbol{\varepsilon}_{\mathrm{v}} / \mathrm{d} \boldsymbol{\varepsilon}_{1}\right)_{\mathrm{f}}$ at failure. It appears that the stress ratio $\left(\boldsymbol{q} / \boldsymbol{p}^{\prime}\right)_{\mathrm{f}}$ for latite basalt increases slightly non-linearly with dilatancy. The triaxial test data on decomposed granite (sand size) reported by Miura and 0-hara ${ }^{4}$ and on Fulung sand presented by Ueng and Chen ${ }^{11}$ are also plotted in Fig. 6 for comparison, which indicate more linear trends compared with 
the latite aggregates. The non-linearity of the basalt response is probably due to its much coarser and angular shape than that of the decomposed granite and Fulung sand, hence making it more prone to degradation upon loading.

\section{I. Energy consumption during particle breakage}

In order to quantify the energy consumption due to particle breakage, the value of the basic friction angle, $\phi_{\mathrm{f}}$, in equation (17) needs to be determined first. For the purpose of estimating $\phi_{\mathrm{f}}$, the last term of equation (19) containing particle breakage can be set to zero, and the resulting apparent (equivalent) friction angle may be denoted by $\phi_{\mathrm{fb}}$, which naturally includes the contribution from particle breakage. Thus equation (19) can now be simplified as follows:

$21 \quad \frac{\boldsymbol{q}}{\boldsymbol{p}^{\prime}}=\frac{\left(1-\frac{\mathrm{d} \boldsymbol{\varepsilon}_{\mathrm{v}}}{\mathrm{d} \boldsymbol{\varepsilon}_{1}}\right) \tan ^{2}\left(45^{\circ}+\frac{\phi_{\mathrm{fb}}}{2}\right)-1}{\frac{2}{3}+\frac{1}{3}\left(1-\frac{\mathrm{d} \boldsymbol{\varepsilon}_{\mathrm{v}}}{\mathrm{d} \boldsymbol{\varepsilon}_{1}}\right) \tan ^{2}\left(45^{\circ}+\frac{\phi_{\mathrm{fb}}}{2}\right)}$

Using the triaxial data of stress ratio $\left(\boldsymbol{q} / \boldsymbol{p}^{\prime}\right)_{\mathrm{f}}$ and dilatancy at failure $\left(1-\mathrm{d} \varepsilon_{\mathrm{V}} / \mathrm{d} \varepsilon_{1}\right)_{\mathrm{f}}$ in equation (21), the value of $\phi_{\mathrm{fb}}$ can be determined, which includes the contribution from particle breakage but excludes the dilatancy effect. The calculated $\phi_{\mathrm{fb}}$ values are plotted against initial confining pressure in Fig. 7, and against the rate of particle breakage at failure $\left(\mathrm{d} B_{\mathrm{g}} / \mathrm{d} \boldsymbol{\varepsilon}_{1}\right)_{\mathrm{f}}$ in Fig. 8. It is evident from Fig. 7 that $\phi_{\mathrm{fb}}$ increases at a diminishing rate with increasing confining pressure. At elevated confining pressure, a greater amount of energy is consumed during particle breakage, which is reflected in the increasing value of $\phi_{\mathrm{fb}}$. A non-linear relationship between $\phi_{\mathrm{fb}}$ and the rate of particle breakage at failure $\left(\mathrm{d} B_{\mathrm{g}} / \mathrm{d} \boldsymbol{\varepsilon}_{1}\right)_{\mathrm{f}}$ is obtained as shown in Fig. 8. By extrapolating this relationship to zero rate of particle breakage (i.e. $\left.\left(\mathrm{d} B_{\mathrm{g}} / \mathrm{d} \varepsilon_{1}\right)_{\mathrm{f}}=0\right)$, the basic friction angle $\left(\phi_{\mathrm{f}}\right)$ can be estimated. The value of $\phi_{\mathrm{f}}$ of latite

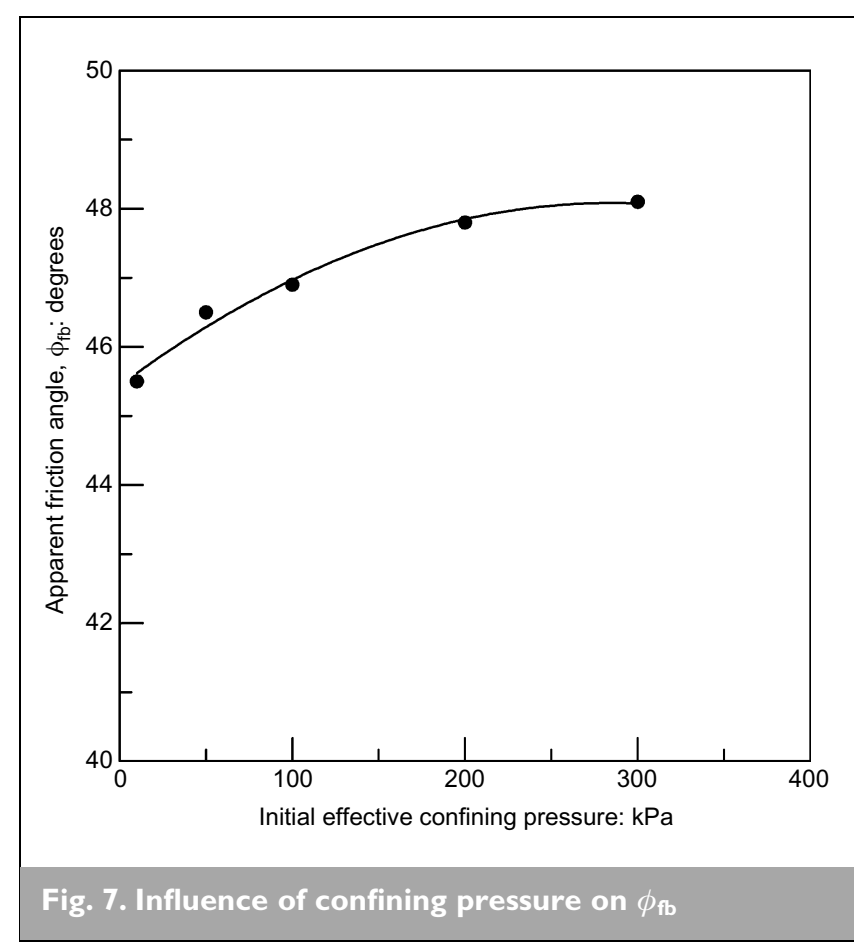

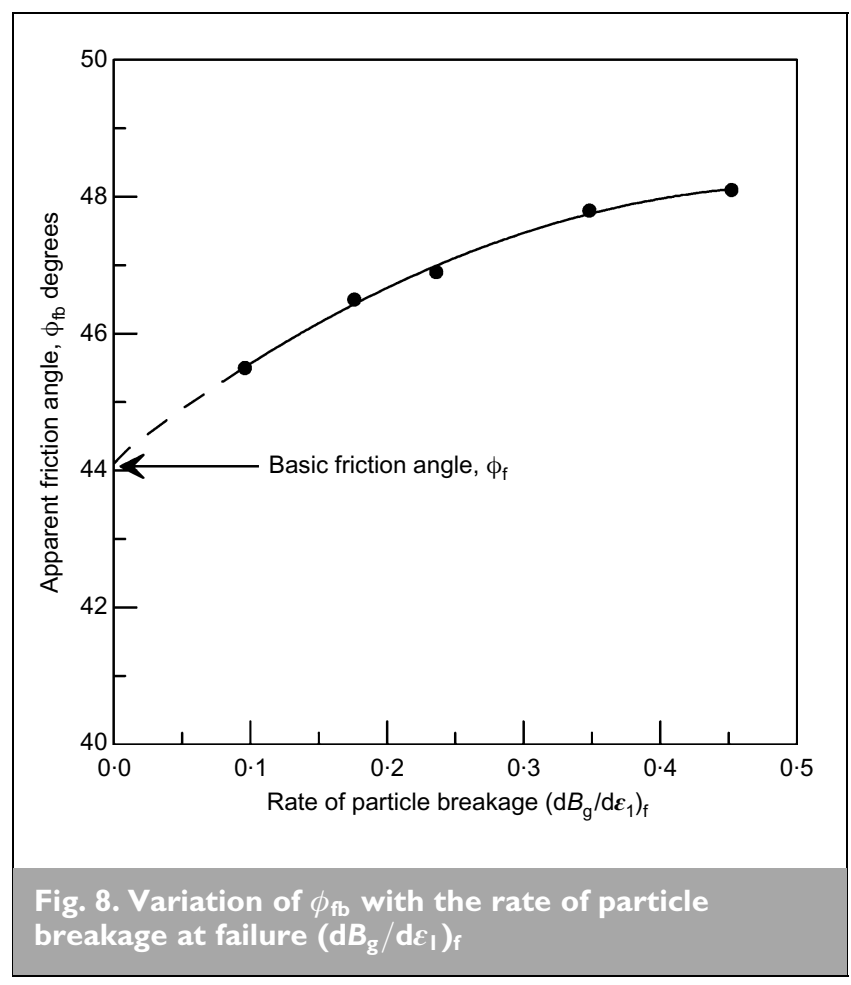

aggregates based on the current triaxial testing is found to be approximately $44^{\circ}$ (see Fig. 8).

The rate of energy consumption due to particle breakage at failure $\left(\mathrm{d} E_{\mathrm{B}} / \mathrm{d} \varepsilon_{1}\right)_{\mathrm{f}}$ can be calculated using equation (17), substituting the above values of $\phi_{\mathrm{f}}$, deviator stress ratio $\left(\boldsymbol{q} / \boldsymbol{p}^{\prime}\right)_{\mathrm{f}}$ and dilatancy $\left(1-\mathrm{d} \boldsymbol{\varepsilon}_{\mathrm{v}} / \mathrm{d} \boldsymbol{\varepsilon}_{1}\right)_{\mathrm{f}}$ at failure. Fig. 9 shows the variations of the rate of energy consumption by particle breakage $\left(\mathrm{d} E_{\mathrm{B}} / \mathrm{d} \varepsilon_{1}\right)_{\mathrm{f}}$ and the rate of particle breakage at failure $\left(\mathrm{d} B_{\mathrm{g}} / \mathrm{d} \boldsymbol{\varepsilon}_{1}\right)_{\mathrm{f}}$ with increasing confining pressure. Both $\left(\mathrm{d} B_{\mathrm{g}} / \mathrm{d} \varepsilon_{1}\right)_{\mathrm{f}}$ and $\left(\mathrm{d} E_{\mathrm{B}} / \mathrm{d} \varepsilon_{1}\right)_{\mathrm{f}}$ increase with increasing confining pressure. It

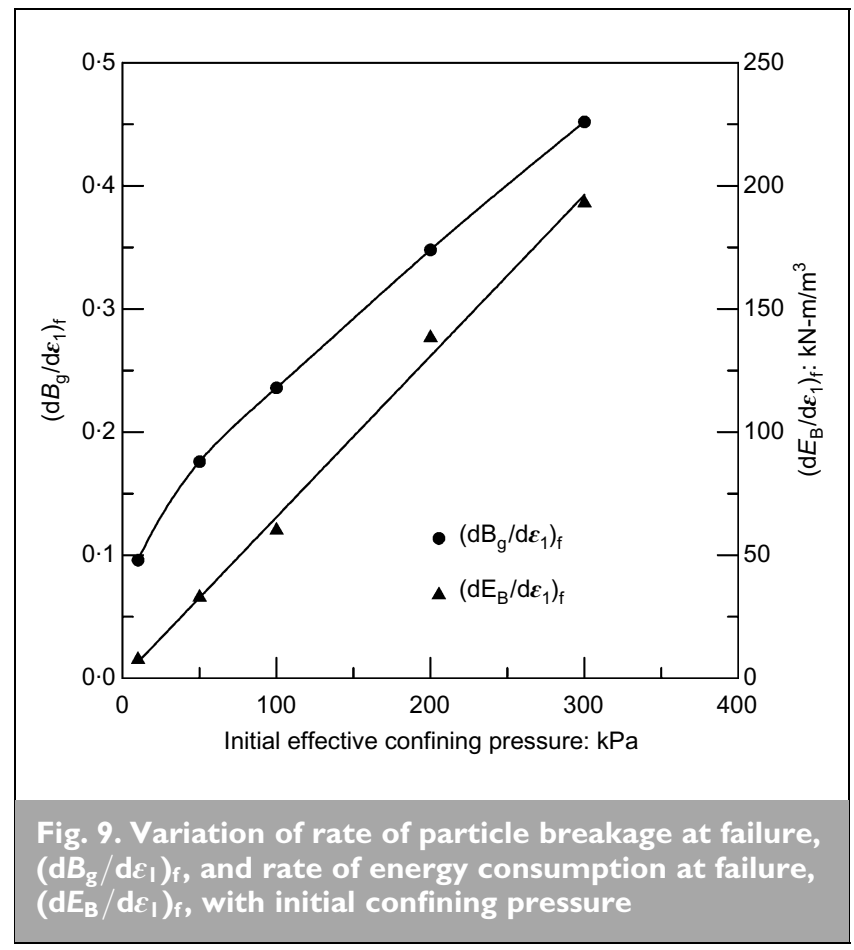


appears in Fig. 10 that the relationship between $\left(\mathrm{d} E_{\mathrm{B}} / \mathrm{d} \boldsymbol{\varepsilon}_{1}\right)_{\mathrm{f}}$ and $\left(\mathrm{d} B_{\mathrm{g}} / \mathrm{d} \varepsilon_{1}\right)_{\mathrm{f}}$ can best be represented by a power relationship:

$$
\left(\frac{\mathrm{d} E_{\mathrm{B}}}{\mathrm{d} \varepsilon_{1}}\right)_{\mathrm{f}}=a\left[\left(\frac{\mathrm{d} B_{\mathrm{g}}}{\mathrm{d} \varepsilon_{1}}\right)_{\mathrm{f}}\right]^{b}
$$

where $a$ and $b$ are empirical constants. For the latite basalt, $a=1195$ and $b=2 \cdot 12$ have been found from the current data.

\subsection{Effect of particle breakage on peak friction angle}

By rearranging the Mohr-Coulomb failure criterion, the peak friction angle $\left(\phi_{\mathrm{p}}\right)$ can be conveniently calculated from the following relationship:

$$
\left(\frac{\boldsymbol{\sigma}_{1}^{\prime}}{\boldsymbol{\sigma}_{3}^{\prime}}\right)_{\mathrm{p}}=\frac{1+\sin \phi_{\mathrm{p}}}{1-\sin \phi_{\mathrm{p}}}
$$

The above conventional equation considers the peak principal stress ratio $\left(\boldsymbol{\sigma}_{1}^{\prime} / \boldsymbol{\sigma}_{3}^{\prime}\right)_{\mathrm{p}}$ to determine the peak friction angle, $\phi_{\mathrm{p}}$, and hence provides an obvious upper bound for the interparticle friction. The basic friction angle, $\phi_{\mathrm{f}}$, evaluated at zero dilatancy and at zero particle breakage provides a lower bound (see Fig. 8), and it is independent of the confining pressure. In this respect, the basic friction angle, $\phi_{\mathrm{f}}$, is about the same as the angle of repose of the material. As explained earlier, the apparent friction angle, $\phi_{\mathrm{fb}}$, includes particle breakage but it is independent of dilatancy.

Figure 11 illustrates the values of various angles of friction with increasing effective confuning pressure. At lower confining pressure, the difference between $\phi_{\mathrm{p}}$ (equation (23)) and $\phi_{\mathrm{fb}}$ (equation (21)) becomes considerable because of the higher dilatancy. At elevated confining pressure, the difference between $\phi_{\mathrm{fb}}$ and $\phi_{\mathrm{f}}$ increases because of the higher rate of

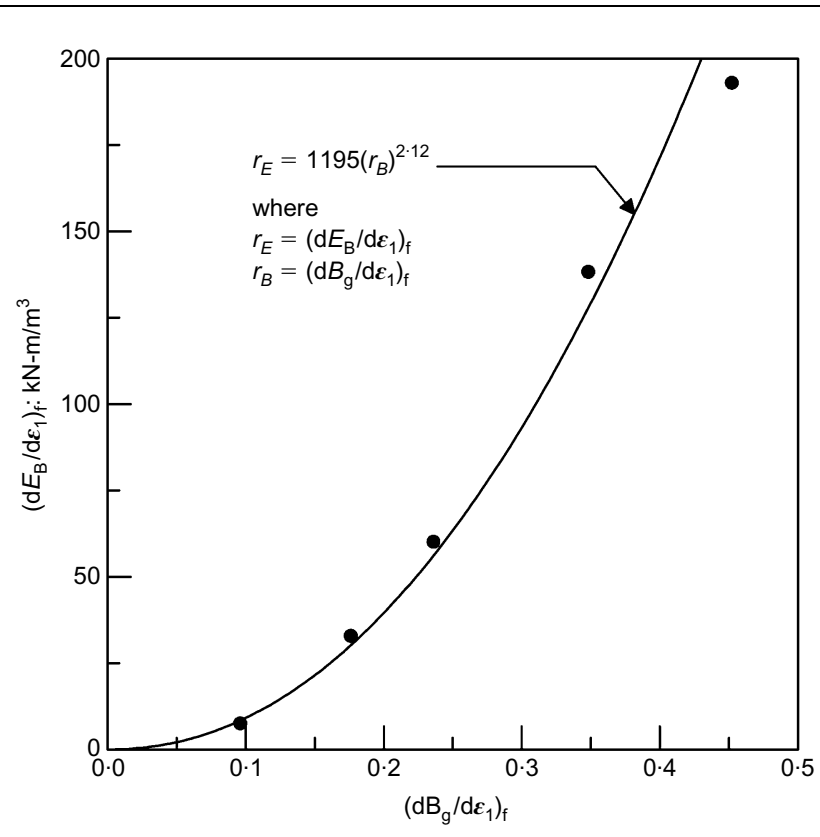

Fig. 10. Rate of energy consumption, $\left(d E_{B} / d \varepsilon_{I}\right)_{f}$, against rate of particle breakage, $\left(d B_{g} / d \varepsilon_{1}\right)_{f}$

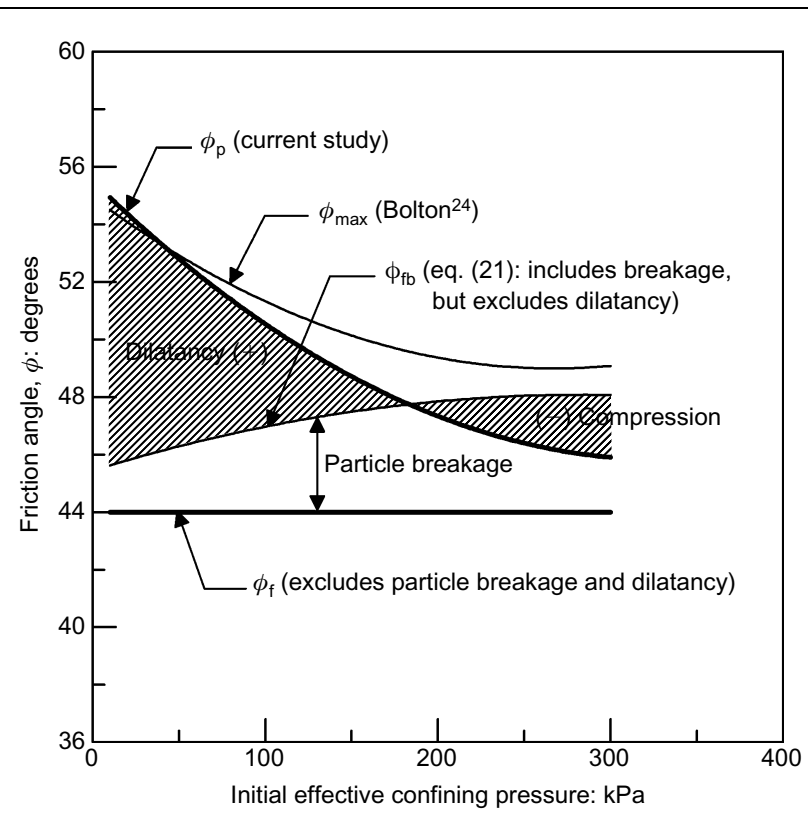

Fig. II. Effect of particle breakage, dilatancy and confining pressure on the friction angle of latite basalt $\left(d_{50}=37.0 \mathrm{~mm}\right)$

particle degradation (i.e. increased energy consumption). The peak friction angle, $\phi_{\mathrm{p}}$, can therefore be considered as the summation of basic friction angle, $\phi_{\mathrm{f}}$, and the effects of dilatancy and particle breakage, as illustrated in Fig. 11. The peak friction angle decreases with increasing confining pressure, and this observation is consistent with previous studies. $^{10,12,23}$ Bolton $^{24}$ modelled the dilatancy-related component of friction angle, $\phi_{\max }-\phi_{\text {crit }}$, for sand as a function of the relative dilatancy index, which is related to the initial compacted density and the effective mean stress at failure. If the value of $\phi_{\mathrm{f}}$ derived in Fig. 8 is considered as the value of $\phi_{\text {crit }}$ for the latite aggregates, then the maximum friction angle, $\phi_{\max }$, can be predicted easily using Bolton's model. The predicted value of $\phi_{\max }$ is obtained by adding the dilatancy component to $\phi_{\text {crit }}$; however, the role of particle breakage is not incorporated. While this is realistic for fine granular media such as sand, Bolton's model may not be accurate for coarser and angular aggregates such as latite basalt, for which particle degradation can be significant. Nevertheless, the predicted $\phi_{\max }$ for latite basalt is shown in Fig. 11 for comparison, which reveals that Bolton's model predicts $\phi_{\max }$ for basalt in close agreement to $\phi_{\mathrm{p}}$ at low confining pressure, where the rate of particle breakage is negligible. However, it seems that Bolton's model overpredicts the maximum friction angle (or dilatancy-related friction component) of coarse aggregates at higher confining pressure. The current model may be used to distinguish clearly the particle breakage component, dilatancy component and basic friction component of the shear strength of angular coarse aggregates.

\section{CONCLUSIONS}

The degree of particle breakage affects the strength characteristics of coarse aggregates. An analytical model has been developed to include the relationship between the 
deviator stress ratio $\left(\boldsymbol{q} / \boldsymbol{p}^{\prime}\right)$, dilatancy, basic friction angle and rate of energy consumption due to particle breakage. Laboratory investigations have been conducted on latite aggregates using a large-scale triaxial apparatus, and the breakage of particles during shearing has been quantified. The results indicate that the apparent friction angle, $\phi_{\mathrm{fb}}$ (which includes particle breakage, but excludes dilatancy effect), increases at a decreasing rate with the higher confining pressure and with the rate of particle breakage. The basic friction angle, $\phi_{\mathrm{f}}$, has been estimated as the value of $\phi_{\mathrm{fb}}$ at zero rate of particle breakage, and is found to be about $44^{\circ}$ for the latite aggregates used in this study. The analytical model has been applied to the test results, and it is shown to be useful in explaining the effects of dilatancy and particle degradation on the variation of friction angle with confining pressures. The findings of this study confirm that the peak friction angle, $\phi_{\mathrm{p}}$, is the summation of basic friction angle, $\phi_{\mathrm{f}}$, and the effects of dilatancy and particle breakage during shearing.

The test results verify that the breakage of aggregates increases with increasing confining pressure, and that the larger aggregates are more vulnerable to degradation. Particle breakage increases with axial strain at a decreasing rate, and continues to increase even after the peak deviator stress. The stress ratio of latite basalt increases slightly non-linearly with dilatancy, and this response may be attributed to the increasing vulnerability of coarser aggregates to degradation upon loading. The rate of energy consumption $\left(\mathrm{d} E_{\mathrm{B}} / \mathrm{d} \varepsilon_{1}\right)_{\mathrm{f}}$ is best represented by a power relationship with the rate of particle breakage $\left(\mathrm{d} B_{\mathrm{g}} / \mathrm{d} \boldsymbol{\varepsilon}_{1}\right)_{\mathrm{f}}$ at failure. The current findings show that, at low confining pressure, latite aggregates exhibit a high peak friction angle associated with greater dilatancy. At elevated confining pressure the effect of dilatancy is small, but the increased particle breakage contributes significantly to the frictional behaviour of coarse aggregates.

The degradation of coarse aggregates under static loading provides an important insight into degradation under cyclic loading. This is because the particle breakage taking place under static loading can be considered as the preliminary modelling step of repeated loading. The extent of particle breakage during the furst stage of cyclic loading is expected to be comparable to that of static loading. Extension of the current model to cyclic loading is still ongoing, and the authors expect to report these findings at a later date.

\section{ACKNOWLEDGEMENTS}

The authors wish to express their sincere gratitude and appreciation to the Australian Research Council (ARC) and Rail Infrastructure Corporation (RIC) of NSW, Australia, for supporting this research project. Continued research on this subject area by the Cooperative Research Centre (CRC) for Railway Engineering and Technologies is also acknowledged.

\section{REFERENCES}

1. TAYLOR D. W. Fundamentals of Soil Mechanics. Wiley, New York, 1948.

2. RoWE P. W. The stress-dilatancy relation for the static equilibrium of an assembly of particles in contact.

Proceedings of the Royal Society of London, Series A, 1962, 269, 500-527.

3. LEE K. L. and SEED H. B. Drained strength characteristics of sand. Journal of the Soil Mechanics and Foundations Divisions, ASCE, 1967, 93, No. SM6, 117-141.

4. MiURA N. and O-HARA S. Particle crushing of decomposed granite soil under shear stresses. Soils and Foundations, 1979, 19, No. 3, 1-14.

5. McDowell G. R., Bolton M. D. and Robertson D. The fractal crushing of granular materials. Journal of the Mechanics and Physics of Solids, 1996, 44, No. 12, 2079-2102.

6. WeIBULL W. A statistical distribution function of wide applicability. Journal of Applied Mechanics, 1951, 18, 293-297.

7. McDowell G. R. and Bolton M. D. On the micromechanics of crushable aggregates. Géotechnique, 1998, 48, No. 5, 667-679.

8. Roscoe K. H., Schofield A. N. and ThURAIRAJAH A. Yield of clays in states wetter than critical. Géotechnique, 1963, 13, 211-240.

9. Schofield A. N. and Wroth C. P. Critical State Soil Mechanics. McGraw-Hill, London, 1968.

10. IndRaRATnA B., IONESCU D. and Christie H. D. Shear behavior of railway ballast based on large-scale triaxial tests. Journal of Geotechnical and Geoenvironmental Engineering, 1998, 124, No. 5, 439-449.

11. Ueng T. S. and Chen T. J. Energy aspects of particle breakage in drained shear of sands. Géotechnique, 2000, 50, No. 1, 65-72.

12. MARSAL R. J. Mechanical properties of rockfill. In Embankment Dam Engineering: Casagrande Volume (Hirschfield R. C. and Poulos S. J. (eds)). Wiley, New York, 1973, pp. 109-200.

13. HARDIN B. 0. Crushing of soil particles. Journal of Geotechnical Engineering, 1985, 111, No. 10, 1177-1192.

14. INDRARATNA B. Large-scale triaxial facility for testing of non-homogeneous materials including rockfill and railway ballast. Australian Geomechanics, 1996, 30, 125-126.

15. STANDARDS AUSTRALIA. Methods for Sampling and Testing Aggregates, Method 21: Aggregate Crushing Value. Standards Australia, Sydney, NSW, 1997, Australian Standard AS 1141.21.

16. Standards Australia. Methods for Sampling and Testing Aggregates, Method 23: Los Angeles Value. Standards Australia, Sydney, NSW, 1995, Australian Standard AS 1141.23.

17. StANDARDS Australia. Methods for Sampling and Testing Aggregates, Method 27: Resistance to Wear by Attrition. Standards Australia, Sydney, NSW, 1995, Australian Standard AS 1141.27.

18. STANDARDS AUSTRALIA. Methods of Testing Rocks for Engineering Purposes, Method 4.1: Rock Strength TestsDetermination of Point Load Strength Index. Standards Australia, Sydney, NSW, 1993, Australian Standard AS 4133.4.1.

19. StANDARDS Australia. Methods of Testing Rocks for Engineering Purposes, Method 4.2: Rock Strength TestsDetermination of Uniaxial Compressive Strength. Standards Australia, Sydney, NSW, 1993. Australian Standard AS 4133.4.2.

20. STANDARDS AUSTRALIA. Methods for Sampling and Testing Aggregates, Method 15: Flakiness Index. Standards Australia, Sydney, NSW, 1999, Australian Standard AS 1141.15. 
21. STANDARDS AUSTRALIA. Methods for Sampling and Testing Aggregates, Method 14: Particle Shape, by Proportional Calliper. Standards Australia, Sydney, NSW, 1995, Australian Standard AS 1141.14.

22. Duncan J. M. and SEED H. B. Corrections for strength test data. Journal of the Soil Mechanics and Foundations
Division, ASCE, 1967, 93, No. 5, 121-137.

23. Charles J. A. and WatTS K. S. The influence of confining pressure on the shear strength of compacted rockfill. Géotechnique, 1980, 30, No. 4, 353-367.

24. BoLton M. D. The strength and dilatancy of sands. Géotechnique, 1986, 36, No. 1, 65-78.

Please email, fax or post your discussion contributions to the secretary by I April 2003: email: mary.henderson@ice.org.uk; fax: +44 (0)20 7799 1325; or post to Mary Henderson, Journals Department, Institution of Civil Engineers, I-7 Great George Street, London SWIP 3AA. 